\title{
LAS RESERVAS DE SUELO PARA VIVIENDA PROTEGIDA: LECCIONES DEL CASO DE VITORIA-GASTEIZ
}

\author{
Javier Burón Cuadrado \\ fi-buron@ej-gv.es \\ Director de Planificación y Procesos Operativos de Vivienda \\ Departamento de Vivienda y Asuntos Sociales del Gobierno Vasco \\ 101010 VITORIA-GASTEIZ (ALAVA) \\ Remisión articulo: 24-8-2006 Remisión definitiva: 19-9-2006
}

Palabras Clave: Políticas públicas de vivienda, Reservas de suelo para Vivienda Protegida, Normativa de Vivienda Protegida

Resumen: Este trabajo pretende ser una demostración empírica, tomando como ejemplo la ciudad de Vitoria-Gasteiz, de los efectos de las reservas de suelo para Vivienda Protegida impuestas por las leyes autonómicas y reflejadas en los planeamientos urbanísticos municipales. Dos son, a nuestro juicio, los principales efectos prácticos de la referida técnica jurídica cuando la misma es aplicada de forma sostenida en el tiempo: en primer lugar la atención directa a una amplia capa de la sociedad y la satisfacción de su necesidad de vivienda a precios ostensiblemente inferiores a los del mercado (con todos los efectos sociales y económicos que esto implica) y en segundo lugar la consiguiente presión sobre el mercado de la vivienda libre que, si la oferta de Vivienda Protegida es suficientemente grande y constante en el tiempo, tiende a limitar la rapidez y los precios de las ventas de Vivienda Libre.

\section{Introducción}

El objeto de este trabajo es la búsqueda de los efectos prácticos de la aplicación de las reservas de suelo para Vivienda Protegida en una Comunidad Autónoma como Euskadi en lasque estas llevan vigentes desde el año 1994 que además siempre han sido las mayores del Estado español en términos cuantitativos ${ }^{1}$.

\footnotetext{
${ }^{1}$ Como es bien conocido en la Comunidad Autónoma del País Vasco existe, desde 1994, ex lege, (Ley 17/1994, de 30 de junio) una reserva para Vivienda Protegida, en los municipios de más de 7.000 habitantes, del 65\% de las nuevas viviendas a construir en suelo urbanizable, que es el $20 \%$ en el caso de las viviendas a construir en suelo urbano. La reciente Ley $2 / 2006$, de 30 de junio, de Suelo y Urbanismo ha elevado esas reservas a un $75 \%$ en suelo urbanizable y un $40 \%$ en suelo urbano y ha rebajado el umbral municipal a los municipios de más de 2.000 habitantes. Estas reservas para Vivienda Protegida siempre han sido las mayores de las existentes en las quince Comunidades Autónomas que disponen de ellas y con los recientes cambios legales, aun más.
} 


\section{La figura de las reservas del suelo para vivienda protegida}

No es objeto de este trabajo hacer un exhaustivo repaso del origen histórico y los precedentes en derecho comparado de las reservas de suelo para Vivienda Protegida pero si entendemos que es necesario hacer un mínimo comentario al respecto ${ }^{2}$.

El derecho es, o al menos debe ser, una técnica social al servicio de, inter alia, la convivencia, la paz social, la prevención de conflictos y la cohesión social. En concreto el derecho urbanístico, debe procurar el equilibrio espacial, económico, social y medioambiental. Y dentro de este conjunto teleológico debe jugar un papel especialmente relevante la producción de viviendas asequible tanto en cantidad como en calidad y localización (estos dos últimos aspectos la mayor parte de las veces son despreciados, pero tienen grandes efectos sociales). Y como es lógico en cualquier contesto público-administrativo, cuando estos fines no los procura el mercado de forma endógena (o como en el caso que nos ocupa, cuando el mercado camina de forma natural en la dirección opuesta) el Estado debe actuar. La vivienda es un presupuesto material y físico del disfrute de la ciudadanía plena. Muchos ciudadanos pueden conseguir ese prius en el mercado sin problemas. Pero otros muchos (jóvenes, colectivos de rentas bajas, mayores, discapacitados, etc) no son considerados por el mercado (en expresión de GAMBARO ${ }^{3}$ el mercado no procesa necesidades -sociales-, solo demandas -económicas solventes-) y deben ser atendidos por las Administraciones Públicas. La ciudadanía plena no puede depender de la renta disponible, al menos en un Estado Social y Democrático de Derecho.

Las ciudades y los pueblos (el territorio antropizado) son sistemas sociales en los que hay que buscar la heterogeneidad de usos del suelo, tipologías de viviendas y mezclas sociales para evitar los conflictos, la exclusión y, como fin último, procurar que se creen verdaderos demoi (pueblos) con capacidad real de ejercitar todos sus derechos fundamentales, es decir demoi con capacidad de ejercer el kratos (poder) que eso, y no otra cosa, es la democracia. La heterogeneidad urbana es pues un presupuesto moderno, o no tan moderno, de la democracia efectiva.

Ante la evidencia de fenómenos como la segregación por abajo (los barrios "problemáticos" de todo tiempo y lugar) y la autosegregación por arriba (las modernas y no solo anglosajonas gated cities) el derecho público del Estado Social y Democrático de Derecho debe reaccionar. Y decimos debe pues las constituciones occidentales, y entre ellas la española de 1978, dejan bien claro que los poderes públicos deben intervenir en el proceso urbanizatorio para garantizar varios fines. En este punto es oportuno poner de relieve el recordatorio del profesor ROGER FERNANDEZ, GERARDO cuando afirma que el artículo 47 de la Constitución española es el único de toda la Carta Magna que prohíbe un tipo de especulación (la ejercida sobre el suelo) y

\footnotetext{
${ }^{2}$ Sobre este tema es interesante la consulta de PONCE SOLÉ, JULI Solidaridad, cohesión social y derecho público, a propósito de las reservas legales de Vivienda Protegida como instrumento de desarrollo urbanístico sostenible, II Seminario Pensando lo local en el nuevo siglo, Fundació Carle Pi i Sunyer, 5 y 6 de febrero de 2004.

3 GAMBARO, A Propieta privata e disciplina usbanistica, Zanichelli, Bolonia, 1977. Los adjetivos ("sociales" y "económicas solventes") son míos.
} 
es un artículo que no deja opción a los poderes públicos, pues en materia de vivienda estos deben intervenir, intervenir y después intervenir ${ }^{4}$.

En el caso español los mandatos del artículo $47^{5}$ son claros y, como ya decían los juristas romanos, in claris non fit interpretario (máxime si tenemos en cuenta el artículo 53.3 de la Constitución como marco de lectura del citado artículo 47 de la Carta Magna):

- promover las condiciones necesarias y establecer las normas pertinentes para hacer efectivo el derecho de la ciudadanía a disfrutar de una vivienda digna y adecuada

- regular la utilización del suelo de acuerdo al interés general

- impedir la especulación

- garantizar la participación de la comunidad en las plusvalías que genere la acción urbanística de los entes públicos.

Como llevar todos estos mandatos a la práctica y a través de que técnicas es algo que debe resolver el legislador ordinario. En el tiempo preconstitucional la legislación española sobre suelo no incorporó expresamente técnica alguna al servicio de la vivienda asequible. Es el texto Refundido de la Ley del Suelo de 1992 el que en sus artículos 3.2 h) y 98.3 permite por primera vez a los poderes locales calificar suelo para vivienda con algún tipo de protección pública ${ }^{6}$. La reacción jurisprudencial fue realmente dura al considerar estas reservas como voluntarias para la propiedad del suelo y en todo caso susceptibles de compensación por parte de lo público ${ }^{7}$. Como quiera que la Sentencia 61/1997 del Tribunal Constitucional declaró inconstitucional, junto con el 80\% de la Ley del Suelo de 1992 los dos artículos citados, la batalla del Tribunal Supremo contra este tipo de reservas pareció haber llegado a un victorioso fin. Pero dado que la referida sentencia del Tribunal Constitucional pone en manos del legislador autonómico el modelo de territorio y ciudad han sido las legislaciones autonómicas las que han resucitado la figura de las reservas de suelo para Vivienda Protegida, siendo como ya hemos dicho la Comunidad Autónoma del País Vasco pionera (la primera) y vanguardia (las reservas más altas) en esta materia.

\footnotetext{
${ }^{4}$ ROGER FERNANDEZ, GERARDO La gestión del suelo para la vivienda social, en el curso de verano de la Universidad Complutense "El derecho a la vivienda y la política local", El Escorial (Madrid), 25 a 29 de julio de 2005.

${ }^{5}$ La bibliografía sobre este precepto constitucional es amplia. Entre otros se puede consultar: BASSOLS COMA, MARTIN Consideraciones sobre el derecho a la vivienda en la Constitución española de 1978, RDU, Madrid, 1983; BELTRAN DE FELIPE, MIGUEL Intervención Administrativa en la vivienda, Editorial Lex Nova, Valladolid, 2000; MUÑOZ CASTILLO, JOSE El derecho a una vivienda digna y adecuada; Editorial Colex, Madrid, 2000; JIMÉNEZ BLANCO, ANTONIO El derecho a una vivienda digna y adecuada en Comentarios a la Constitución social y económica de España, Editorial Comares, Granada, 2002; PISARELLO, GERARDO Vivienda para todos, un derecho en (de)construcción, Editorial Icaria, Barcelona, 2003.

${ }^{6}$ Para ser totalmente justos es necesario señalar que las reservas de suelo para Vivienda Protegida tienen su antecedente en el Anteproyecto de Ley sobre Régimen Urbanístico de Suelo y Valoraciones que en 1987 redactó el profesor ROCA CLADERA, JOSEP para el Gobierno Vasco. Aunque en el seno de este proyecto la técnica jurídica de las reservas acabara siendo modificada hasta hacer difícil su reconocimiento. Y a mayor abundamiento, el Anteproyecto vasco de 1987 bebía en las fuentes del PGOU de Madrid de 1985 que incluyó en el cálculo del aprovechamiento medio un $70 \%$ de VPO

${ }^{7}$ Sobre la jurisprudencia del Tribunal Supremo en este punto se puede consultar el trabajo ya citado de PONCE SOLÉ, JULI Solidaridad, cohesión social y derecho público, a propósito de las reservas legales de Vivienda Protegida como instrumento de desarrollo urbanístico sostenible, II Seminario Pensando lo local en el nuevo siglo, Fundació Carle Pi i Sunyer, 5 y 6 de febrero de 2004; páginas 189 a 193 en las que habla el autor de "arbitrio judicial".
} 
Frente a quienes entienden que estas reservas violan la autonomía local y el derecho a la propiedad y son claramente contrarias al marco general de los estados occidentales hay que decir que la Ley 17/1994 de la Comunidad Autónoma del País Vasco que introdujo esta técnica en España, además de ser perfectamente constitucional por respetar el tenor literal de los artículos 33 y 140 de nuestra Constitución, viene precedida o acompañada de numerosos ejemplos en países de nuestro entorno cultural.

Debemos citar al menos la Loi d'orientation pour la ville y el Code de la Construction et de l'habitation francés que imponen la obligación a los municipios de cierto tamaño de llegar a tener en el plazo de 20 años un $20 \%$ de sus viviendas en alquiler social. También es necesario referirnos a las técnicas presentes en el mundo anglosajón, inclusionary zoning, affordable housing obligations y planning obligations en Estados Unidos, Canadá y Reino Unido respectivamente que imponen la obligación a los developers (promotores) de construir un determinado porcentaje de vivienda de precio accesible, generalmente en alquiler. Todas estas técnicas (así como algunas más novedosas aún, vg las cuotas étnicas en los parques de Vivienda Protegida en Singapur) llevan más de 15 años presentes en las legislaciones de estos estados y no se puede decir que las reservas para Vivienda Protegida de la Ley 17/1994 de la Comunidad Autónoma del País Vasco nacieran ni en el vacío ni huérfanas de hermanas y primas en otras partes del planeta.

\section{Las peculiaridades del Sistema Vasco}

Para enjuiciar las reservas de suelo para Vivienda Protegida en Euskadi debemos tener presenta algunas de las peculiaridades de la normativa sobre vivienda de esta Comunidad Autónoma ${ }^{8}$.

En primer lugar conviene recordar que la Vivienda Protegida en Euskadi en estos momentos supone una de cada tres nuevas viviendas construidas, mientras que en el conjunto del Estado español las Viviendas Protegidas están en el entorno de una de cada trece de las nuevas viviendas construidas. Se entenderá fácilmente que el régimen jurídico de la Vivienda Protegida tiene gran impacto en la vida cotidiana de miles de ciudadanos vascos (por no hablar de la realidad alavesa en la que una de cada dos nuevas viviendas es una Vivienda Protegida). No estamos hablando con la Vivienda Protegida de un componente residual del mercado de la vivienda, sino de uno de sus elementos centrales.

En segundo lugar hay que tener en cuenta las peculiaridades jurídicas de la Vivienda Protegida en la Comunidad Autónoma del País Vasco. Esta está conceptuada por la normativa vasca ${ }^{9}$

\footnotetext{
${ }^{8}$ Sobre el rumbo actual de los modelos jurídicos de las Comunidades Autónomas en materia de vivienda, PONCE SOLÉ, JULI Algunas reflexiones sobre la competencia en materia de vivienda y las tendencias actuales en su ejercicio, Informe Comunidades Autónomas 2004, Instituto de Derecho Público, Barcelona 2005. Sobre la evolución de la política de vivienda en España existe abundante bibliografía. Entre otros, se puede consultar: VILLAR EZCURRA, JOSE LUIS La protección pública a la vivienda, Editorial Montecorvo, Madrid, 1981; GOMÁ, RICARD Las políticas de viviendas en las Comunidades Autónomas, dentro del volumen Estado de Bienestar y Comunidades Autónomas, Editorial Tecnos, Madrid, 2003; GARRIDO, PILAR EI derecho a disfrutar de una vivienda digna y adecuada, en Los principios rectores de la política social y económica, Editorial Biblioteca Nueva, Madrid, 2004; GOMEZ JIMENEZ, MARIA LUISA La intervención Administrativa en la Vivienda en España 1938-2005, Editorial Montecorvo, Madrid, 2006.
} 
como un patrimonio inmobiliario que debe tener como destino la satisfacción del derecho constitucional de acceso a una vivienda digna de los ciudadanos más necesitados de tutela pública. Como tal, estas Viviendas Protegidas están adscritas funcionalmente a la satisfacción de una necesidad social y con ellas ningún particular debe poder lucrarse y monetarizar una plusvalía de forma privada e individual, dado que son parte de un servicio público ${ }^{10}$.

Una vez tomada esta opción de partida, la normativa vasca de Vivienda Protegida despliega una serie de medidas que deben ser leídas de forma conjunta e indisoluble y que entendidas de esa forma integral son ciertamente novedosas en el panorama estatal.

\section{1.- La calificación permanente (Artículo 9.1 del Decreto 315)}

La calificación permanente de todo tipo de Viviendas Protegidas es una novedad no solo en Euskadi, sino también en el conjunto del Estado ${ }^{11}$. Las Viviendas Protegidas son, o al menos

${ }^{9}$ El corpus normativo vasco sobre Vivienda Protegida está constituido por las siguientes normas:

- Decreto 315/2002, de 30 de diciembre, sobre régimen de VPO y medidas financieras en materia de vivienda y suelo y Decreto 290/2003, de 25 de noviembre por el que se modifica el Decreto sobre régimen de VPO y medidas financieras en materia de vivienda y suelo.

- Orden de 25 de agosto de 2003 del Consejero del Departamento de Vivienda y Asuntos Sociales, sobre determinación de precios máximos de VPO (modificada por la Orden de 1 de agosto de 2004).

- $\quad$ Orden de 30 de diciembre de 2002, del Consejero de Vivienda y Asuntos Sociales, por la que se aprueban las Ordenanzas de Diseño de VPO.

- $\quad$ Orden de 30 de diciembre de 2002, del Consejero de Vivienda y Asuntos Sociales, sobre circunstancias de necesidad de vivienda.

- Orden de 14 de junio de 2002, del Consejero de Vivienda y Asuntos Sociales, sobre procedimiento de adjudicación de VPO (del Gobierno Vasco).

- Orden de 18 de agosto de 2003, del Consejero de Vivienda y Asuntos Sociales, sobre procedimiento de adjudicación de VPO a que se refiere el artículo 12 del Decreto 315/2002. (promociones privadas).

- Orden de 26 de febrero de 2004, del Consejero de Vivienda y Asuntos Sociales, sobre procedimiento de adjudicación de VPO a que se refiere el artículo 11-4 del Decreto 315/2002 (promociones municipales).

- Orden de 30 de junio de 2004, del Consejero de Vivienda y Asuntos Sociales, sobre procedimiento de adjudicación de promociones privadas de viviendas de protección oficial llevadas a cabo por cooperativas, comunidades de bienes o promoción para uso propio.

- $\quad$ Ley $7 / 1988$, de 15 de Abril, de derecho preferente de adquisición en las transmisiones de VPO a favor de la Administración de la Comunidad Autónoma de Euskadi y su norma de desarrollo el Decreto 103/1997.

- $\quad$ Ley 2/2006, de 30 de junio, de Suelo y Urbanismo de la Comunidad Autónoma del País Vasco.

${ }^{10}$ Compartimos la defensa de la vivienda como un servicio público hecha en el trabajo antes citado PONCE SOLÉ, JULI Solidaridad, cohesión social y derecho público, a propósito de las reservas legales de Vivienda Protegida como instrumento de desarrollo urbanístico sostenible, II Seminario Pensando lo local en el nuevo siglo, Fundació Carle Pi i Sunyer, 5 y 6 de febrero de 2004 que, en este punto, tiene sus antecedentes en BASSOLS COMA, MARTIN Consideraciones sobre el derecho a la vivienda en la Constitución española de 1978, RDU, Madrid, 1983 y TEJEDOR BIELSA, JULIO CESAR en, entre otros trabajos, Nuevos desarrollos normativos en materia de vivienda en Aragón, Cuadernos de Derecho Local, $n^{\circ}$ 7, Barcelona, febrero 2005.

${ }^{11}$ En el conjunto del Estado se dan básicamente tres opciones en cuanto a la calificación de las Viviendas Protegidas:

- Las Comunidades Autónomas que han optado por la calificación definitiva o cuasidefinitiva. La primera fue la Comunidad Autónoma del País Vasco en el año 2002 y después le siguieron Catalunya (90 años), Extremadura (permanente) y Asturias (vida útil de la vivienda) todas ellas en el año 2004.

- Las Comunidades Autónomas que se mantienen, para sus propias tipologías autonómicas de Vivienda Protegida, más o menos, en el nivel marcado por el Plan Estatal 2005-2009 para favorecer el acceso de los ciudadanos a la vivienda (30 años, susceptibles de ampliación por las Comunidades Autónomas)

- Las Comunidades Autónomas que, a través de diferentes tipologías autonómicas de Vivienda Protegida reducen el periodo de calificación de las mismas. Destacan en este campo las Vivienda de Protección Pública destinadas al alquiler con opción de compra de la Comunidad Autónoma de Madrid descalificable a los 7 años, pero también debemos citar las Vivienda Protegida autonómica descalificable a los 15 años en 
así lo entendemos nosotros, un patrimonio inmobiliario construido con el dinero de los contribuyentes (han aportado más los que más tienen) y/o gracias a la existencia de reservas de suelo delimitadas por ley a favor de la comunidad y que deben tener como destino la satisfacción del derecho constitucional de acceso a una vivienda digna de los ciudadanos más necesitados de tutela pública (deben recibir más los que menos tienen). El patrimonio inmobiliario que constituyen las Viviendas de Protección Oficial puede y debe rotar entre aquellos ciudadanos necesitados de vivienda, pero en ningún caso se debe producir un lucro privado en las operaciones de cambio de titular. Por todo lo anterior desde diciembre de 2002 todas las nuevas Viviendas de Protección Oficial promovidas en Euskadi estarán calificadas como tal de por vida.

Llegados a este punto es importante que reflexionemos sobre que implica esta calificación permanente en el instituto de la propiedad privada ${ }^{12}$. En principio cabe señalar que ningún tipo de propiedad, ni siquiera la propiedad privada pura, sigue el concepto romano de propiedad (uti et abutendi), pues toda la propiedad está, ex constituione, está delimitada por su función social (artículo 33.2 de la Constitución) y toda la riqueza, sea cual sea su titularidad, está subordinada al interés general (artículo 128.1 de la Constitución). De la misma manera cabria señalar que las Viviendas de Protección Oficial no pueden asimilarse sin más a la categoría de dominio público. Ya sabemos lo que no son, pero debemos pasar a una definición positiva de lo que son.

Desde nuestro punto de vista, en el caso de las Viviendas Protegidas calificadas de por vida en Euskadi estamos ante un ejemplo más de propiedad privada fuertemente intervenida por el Estado. Como en los casos del patrimonio histórico-artístico, la propiedad intelectual o la industrial, en el caso de la Vivienda Protegida vasca asistimos a una propiedad privada penetrada por una serie de limitaciones impuestas por razones de interés general. Las Viviendas Protegidas deben tener como destinatarios a la parte de la ciudadanía más necesitada de tutela pública. Por ello, el acceso a este tipo de propiedad esta fuertemente intervenido por la Administración, su uso está regulado y es inspeccionado para comprobar que es el correcto y las segundas y posteriores transmisiones están sometidas a un fuerte aparato

Andalucía, Cantabria o Valencia y las Viviendas de Precio Tasado descalificables a los 10 años en las Islas Baleares o Castilla La Mancha.

El Real Decreto 801/2005, de 1 de julio, por el que se aprueba el "Plan Estatal 2005-2008, para favorecer el acceso de los ciudadanos a la vivienda" fija en su artículo 5 los 30 años como plazo general descalificación de las Viviendas de Protección Oficial que hayan recibido ayudas del plan estatal, sin perjuicio de que las Comunidades Autónomas puedan ampliar este plazo. En su primera redacción el Real Decreto fijaba como plazo de calificación "toda su vida útil (de la vivienda), sin posibilidad de descalificación voluntaria, salvo las viviendas protegidas de nueva construcción para arrendamiento, de renta concertada ...". La presión de diferentes Comunidades Autónomas a lo largo de los meses de mayo y junio de 2005 aconsejó al Ministerio de la Vivienda dejar el plazo de calificación de las viviendas del plan estatal en los referidos 30 años, truncando un intento del Ministerio por evolucionar hacia parámetros vascos, catalanes, extremeños o asturianos.

\footnotetext{
${ }^{12}$ Obviamente me estoy refiriendo al estatuto de la propiedad privada de los titulares de una Vivienda Protegida con posterioridad a la adjudicación de la misma por parte del promotor (público o privado). Dejo de lado el impacto, evidente, de la configuración normativa de la Vivienda Protegida sobre el estatuto de la propiedad de los titulares privados de suelos que se ven obligados por ley y planeamiento a promover determinadas cantidades de este tipo de viviendas sobre sus suelos. Sobre este último asunto se puede consultar la abundante bibliografía de autores que han tratado con profusión este tema como ROGER FERNANDEZ, GERARDO, ALFONSO PAREJO LUCIANO, GARCIABELLIDO JAVIER, MENENDEZ REXACH ANGEL, VAQUER CABALLERIA MARCOS O ROCA CLADERA JOSEP.
} 
de controles y garantías para evitar el fraude y procurar que los siguientes titulares sean personas también dignas de la tutela pública.

Estamos pues ante lo que el profesor PAREJO, LUCIANO ${ }^{13}$ llama una propiedad privada sometida a múltiples servidumbres públicas como consecuencia del interés general que está en juego en la materia. Estamos también ante una propiedad privada en la que su función social es mucho más presente o explícita que en el resto de supuestos de propiedad privada. Por lo tanto, debemos concluir que estamos ante una propiedad privada sui generis de características técnicas y económicas tasadas normativamente y que, desde el punto de vista jurídico, tiene muy poco que ver con la vivienda libre.

\section{2.- Los procedimientos públicos y reglados de adjudicación de toda la vivienda}

Para ser beneficiario de una Vivienda Protegida en Euskadi es necesario explicar que es el Servicio Vasco de Vivienda - Etxebide, es decir el Registro de solicitantes de vivienda. En la Comunidad Autónoma Vasca existe un Registro de solicitantes de Vivienda Protegida donde deben inscribirse las personas interesadas en ser demandantes de este tipo de viviendas. Etxebide es el primer y más poderoso instrumento con que cuenta la Administración para conocer, cual es la demanda y las diferentes necesidades de vivienda que tiene parte de la sociedad vasca. Etxebide es un Registro abierto de forma permanente y no está vinculado a promociones concretas, lo que significa que una vez dado de alta se tiene la posibilidad de entrar en todos los procedimientos de adjudicación de vivienda en los que se cumplan las condiciones establecidas en cada caso, sin más obligación que renovar esa inscripción cada cuatro años (y mantener informada a la Administración de los cambios que se produzcan en el expediente: domicilio de notificación, teléfono, domicilio de empadronamiento, etc) ${ }^{14}$.

${ }^{13}$ PAREJO, LUCIANO y GARCIA DE ENTERRÍA, EDUARDO Lecciones de Derecho Urbanístico, Madrid, Civitas, 1981.

${ }^{14}$ Un registro con estas características (gestor integral de la demanda de Vivienda Protegida de toda una Comunidad Autónoma y mecanismo de adjudicación del conjunto de bienes y servicios públicos vinculados a la Vivienda Protegida desde el año 1997) no existe en ninguna Comunidad Autónoma del Estado español, con la única excepción del Servicio Toc Toc de Aragón (a partir de la Ley 9/2004, de 20 de diciembre, de reforma de la Ley 24/2003, de 26 de diciembre, de medidas urgentes de política de vivienda protegida). Las Comunidades Autónomas que más se acercan al modelo vasco (además en Aragón) pueden ser Asturias (que ya dispone de un registro para estudiar la demandan que pretende convertirse en un sistema de adjudicación de Vivienda Protegida creado por Resolución de 27 de octubre de 2003 de la Consejera de Vivienda y Asuntos Sociales del Principado), Catalunya (que a través de la Sociedad Pública ADIGSA pretende coordinar todos los registros y sistema de adjudicación municipales con un registro único creado por la DA $4^{\text {a }}$ del Decreto 454/2004) y Extremadura (que dispone de un registro de demandantes que son baremados a la hora de acceder a las Viviendas de Protección Oficial desde el Decreto 186/2004 que regula el Plan de Vivienda y Suelo 2004-2007). También debemos reseñar que La Rioja, Navarra y las Islas Baleares han creado en los años 2004 y 2005 una serie de registros que tienen la vocación de contener la demanda de Vivienda Protegida de la Comunidad Autónoma y ser instrumento, de una u otra manera, de adjudicación de la misma, aunque todavía es pronto para medir su desempeño y conocer su verdadero carácter. Por otra parte, Andalucía, Canarias, Cantabria, Galicia, Madrid, Murcia y Valencia no disponen de registro de ningún tipo ni se tiene noticia de proyectos al respecto. Y por completar el cuadro Castilla León dispone de un registro solo para personas con discapacidad y viviendas adaptadas y Castilla y La Mancha está desarrollando un registro para el control de las segundas y posteriores transmisiones de VPO. Todo lo anterior debe enmarcarse en el contexto del debate y aprobación del Real Decreto 801/2005, de 1 de julio, por el que se aprueba el "Plan Estatal 2005-2008, para favorecer el acceso de los ciudadanos a la vivienda". El artículo 13.7 del Real Decreto establece la obligatoriedad de los registros de demandantes en las Comunidades Autónomas para controlar los procesos de adjudicación y venta de las Viviendas Protegidas, pero en el siguiente párrafo acepta la existencia de otros procedimientos autonómicos que garanticen el mismo objetivo (principios de igualdad, publicidad, concurrencia, así como eliminar cualquier tipo de fraude en las primeras y posteriores 
La inscripción en Etxebide es el paso previo al acceso a una Vivienda Protegida, teniendo siempre presente que para acceder a una de estas viviendas, sea en derecho de superficie, compra o arrendamiento, es necesario además cumplir los requisitos que exija la normativa general y cada promoción en concreto.

Para ser dado de alta en el Registro es necesario cumplir los siguientes requisitos:

- Residencia en cualquier municipio del País Vasco, que será acreditada mediante el correspondiente certificado de empadronamiento en el que conste la antigüedad.

- Carecer todos los miembros de la unidad convivencial de vivienda en propiedad, nuda propiedad, derecho de superficie o usufructo.

- Acreditar unos ingresos entre el mínimo y máximo que exija la normativa (en estos momentos, entre 3.000 y 15.100 euros para el alquiler de Vivienda Social, entre 3.000 y 21.100 para el alquiler de Vivienda de Protección Oficial y entre 9.000 y 33.100 euros para el derecho de superficie y la propiedad de la VPO y entre 9.000 y 43.000 para esos regímenes de acceso en el caso de la Vivienda de Precio Tasado).

No debemos confundir los requisitos para ser dado de alta en Etxebide con los requisitos para ser adjudicatario de una Vivienda Protegida. En parte son requisitos concurrentes (empadronamiento, carencia de vivienda y determinados ingresos), pero conceptualmente son cosas distintas. Para poder ser adjudicatario de Vivienda Protegida es necesario cumplir los siguientes requisitos:

- Ser mayor de edad o estar emancipado.

- Residencia en cualquier municipio del País Vasco.

- Tener necesidad de vivienda. Fundamentalmente carecer todos los miembros de la unidad convivencial de vivienda en propiedad, nuda propiedad, derecho de superficie o usufructo durante los dos años inmediatamente anteriores a:

- la fecha de publicación de la Orden del Consejero que dé inicio al procedimiento de adjudicación de viviendas

- la fecha de calificación provisional, en el supuesto de promociones privadas

- la fecha de presentación del visado en segundas y posteriores transmisiones.

- Acreditar unos ingresos entre el mínimo y máximo que exija la normativa.

- No haber sido adjudicatario de otra vivienda de protección oficial en los dos años anteriores, aunque los beneficiarios de vivienda en arrendamiento podrán ser posteriormente beneficiarios de vivienda en derecho de superficie.

transmisiones) sin mucha mayor concreción que la rendición de cuentas en la Comisión Bilateral de Seguimiento del Plan. Este texto no era el originariamente previsto por el Ministerio, dado que el artículo 13.7 en su redacción originaria establecía de forma mucho más taxativa que "la venta y adjudicación de las viviendas acogidas a este Real Decreto, hayan o no obtenido ayudas financieras a la vivienda, habrá de efectuarse a demandantes inscritos en los registros públicos establecidos al efecto por las Comunidades Autónomos y Ciudades Autónomas de Ceuta y Melilla, según los procedimientos que las mismas determinen. En este tema, como en el de la duración de la calificación, el Ministerio operó a lo largo de los meses de mayo y junio del 2005 un claro viraje. 
El sorteo es el principio general en materia de adjudicación de Vivienda Protegida. Frente a otros sistemas autonómicos que han optado por el baremo, en la Comunidad Autónoma del País Vasco hemos optado por un sistema, el de sorteo, que combinado con unos cupos de discriminación positiva o atención preferente, posibilitan la adjudicación transparente y social de toda la Vivienda Protegida, con independencia de quien sea el promotor de la misma ${ }^{15}$.

La sucesión del Decreto 315, la Orden de procedimiento de Vivienda de Protección Oficial y las órdenes homólogas de ayuntamientos, promotores privados y cooperativas de Vivienda de Protección Oficial cierra un círculo en la regulación de los procedimientos a través de los cuales la ciudadanía puede acceder en pie de igualdad a la Vivienda Protegida en Euskadi. Como consecuencia de lo anterior se impone el sorteo como forma de adjudicar toda la Vivienda de Protección Oficial vasca con independencia de su promotor ${ }^{16}$.

Este sistema integral se basa en los principio de publicidad, transparencia y concurrencia pública como principales armas contra el fraude en materia de Vivienda Protegida, todo ello sin perder de vista el carácter social de estas adjudicaciones antes reseñado.

\section{3.- La huida de la venta de la vivienda protegida}

El Gobierno Vasco no vende Vivienda Protegida a los adjudicatarios, sino que o la cede en régimen de alquiler o en derecho de superficie a 75 años.

El efecto conjunto de la calificación indefinida de las Viviendas Protegidas y la adjudicación exclusivamente en derecho de superficie o alquiler es, como se puede comprender, demoledor para las espurias perspectivas de lucro privado futuro.

\section{4.- El control del mercado secundario de vivienda protegida}

El Gobierno Vasco ejerce un fuerte control sobre las transmisiones de Vivienda Protegida cedida en derecho de superficie (es un derecho real transmisible en el mercado) y en propiedad (las Viviendas Protegidas que anteriormente se vendieron).

\footnotetext{
${ }^{15}$ Frente a la extendida idea del sorteo de Vivienda Protegida como un "rifa" o "lotería" regida solo por el azar, creo que es interesante conocer las siguientes estadísticas del sistema Etxebide que muestran que el sorteo con cupos combina transparencia con una fuerte política social. En los años 2001 a 2004 las adjudicaciones de Vivienda Protegida de Etxebide han tenido como destinatarios a los siguientes colectivos: discapacitados $2.7 \%$, familias monoparentales 3.6 $\%$, familias numerosas $0.1 \%$, demandantes por más de cuatro años $1 \%$ (cupo que solo ha operado en el año 2004), jóvenes menores de 35 años 70.3\% y cupo general $22.3 \%$. En el mismo periodo 2001-2004 las adjudicaciones de Etxebide han tenido como destino a demandantes inscritos con los siguientes tramos de ingresos: 3.000 y 9.000 euros el $22 \%, 9.000$ y 15.100 euros el $50.4 \%, 15.100$ y 21.100 euros el $19.3 \%, 21.100$ y 27.100 euros el $6.5 \%, 27.100$ y 33.100 euros el $1.8 \%$. Como se puede apreciar estas adjudicaciones son cualquier cosa menos una rifa ciega y constituyen un elemento central de la política social en materia de vivienda del Gobierno Vasco.

${ }^{16}$ Este sistema es novedoso en el plano estatal no solo por las cautelas que se ponen a las adjudicaciones públicas de Vivienda Protegida sino también porque las adjudicaciones privadas están sometidas también a las garantías propias de Etxebide, cosa que no ocurre de forma integral en ninguna Comunidad Autónoma hasta la fecha (aunque nos consta que en Asturias, Catalunya y Aragón se están dando pasos en este sentido).
} 
El artículo 26 del Decreto 315 / 2002 y Anexo I del Decreto 315 / 2002 establecen las siguientes obligaciones:

- visado de los contratos de compraventa y alquiler de Vivienda Protegida por parte del Gobierno Vasco

- exigencia en este trámite de visado del cumplimiento de los requisitos de Vivienda Protegida para los adquirentes o inquilinos (especialmente importante en materia de precios máximos de venta y alquiler).

- Ios Notarios deberán de forma inexcusable comprobar que dichas operaciones han obtenido el correspondiente visado; sin dicho visado, las transmisiones no se podrán elevar a escritura pública ni inscribirse en el Registro de la Propiedad ${ }^{17}$.

Este engranaje Gobierno Vasco, notarios y registradores de la propiedad está funcionando, hasta la fecha, de manera eficaz para garantizar que todas las segundas y posteriores transmisiones de Vivienda Protegida se someten a las condiciones reglamentarias.

\section{5.- El ejercicio del derecho de tanteo y retracto sobre la vivienda protegida}

El ejercicio del derecho de adquisición permanente (tanteo y retracto) se regula en la Ley 7/1988, de 15 de Abril, de derecho preferente de adquisición en las transmisiones de viviendas de protección oficial a favor de la Administración de la Comunidad Autónoma de Euskadi ${ }^{18}$ y su norma de desarrollo el Decreto 103/1997, de 6 de mayo, de desarrollo de la Ley 7/1988, de 15 de abril, sobre derecho preferente de adquisición a favor de la Administración de la Comunidad Autónoma del País Vasco en las transmisiones de viviendas de protección oficial.

Esta norma afecta a las Viviendas Protegidas calificadas con posterioridad al 12 de mayo de 1988 que están sujetas al tanteo y retracto de la Administración en segundas y posteriores transmisiones onerosas. Esta prescripción existe desde 1988 pero prácticamente no se ha puesto en práctica hasta hace cuatro años. En estos momentos el Gobierno Vasco ejerce el derecho de tanteo y retracto sobre todas las segundas y posteriores transmisiones que se dan en Euskadi, como medida adicional para garantizar el cumplimiento de las prescripciones

\footnotetext{
${ }^{17}$ Todo esto es de aplicación a todas las viviendas con calificación de protección oficial vigente, independientemente de su sujeción a la ley $7 / 1988$ de 15 de abril de derecho preferente de adquisición en las transmisiones de viviendas de protección oficial a favor de la Administración de la Comunidad Autónoma de Euskadi.

${ }^{18}$ Como en algún otro aspecto, en este campo la Comunidad Autónoma del País Vasco fue precursora de futuros desarrollos, pues a la norma legal de 1988 que reconoce el derecho de adquisición preferente a favor de la Administración le han seguido desde finales de los años noventa normas legales o reglamentarias en casi todas las Comunidades Autónomas, aunque la tendencia se ha acelerado a partir del año 2004. Sin embargo, conviene resaltar que muchas Comunidades Autónomas han regulado el instituto del tanteo y retracto pero no lo aplican (aduciendo razones de tipo presupuestario, pero también un pretendido conflicto con la normativa civil). También es digno de reseñarse que muchas Comunidades Autónomas han regulado el tanteo y retracto de Vivienda Protegida a favor de la Comunidad Autónoma autoimponiéndose, de forma innecesaria a mi juicio, los límites propios del tanteo convencional civil (por ejemplo el exiguo plazo de los 10 años en Andalucía, Cantabria, Castilla y León, Galicia o La Rioja, la tendencia a aplicarlo solo a Viviendas de Protección Oficial de promoción puramente pública como en el caso de Canarias, Cantabria o Islas Baleares o el dejarlo directamente en manos de los promotores privados -pacto a incluir entre el promotor privado de Vivienda Protegida y el adquirente en el contrato de compraventa- como ocurre en Andalucía). Finalmente podemos reseñar que Aragón, Catalunya, Extremadura y Asturias están implantando modelos similares al vasco en los que la calificación permanente (permanente de forma expresa, por noventa años o toda la vida útil de la vivienda) se combina con la posibilidad de ejercer el derecho de tanteo y retracto en todas las segundas y posteriores transmisiones de Vivienda Protegida.
} 
reseñadas anteriormente en el apartado 3.4. De hecho, hemos pasado de los cuatro tanteos y retractos de 1994, a los más de 100 del 2004. A lo que hay que añadir las ofertas de venta que empiezan a ser frecuentes, como consecuencia de la asunción de los propietarios de Vivienda Protegida de que su vivienda va a ser tanteada con toda seguridad en caso de intento de transmisión en el mercado. De hecho, en estos momentos en la Comunidad Autónoma del País Vasco nadie vende una Vivienda Protegida a un particular, pues el Gobierno Vasco se está haciendo cargo de todas las transacciones, pasando inmediatamente a adjudicarlas a demandantes inscritos en Etxebide.

\section{6.- La inspección sobre el uso de la vivienda protegida}

Por primera vez desde la consecución del autogobierno se ha puesto en marcha un operativo dirigido por el Departamento de Vivienda y Asuntos Sociales del Gobierno Vasco especializado en las labores de inspección del uso del parque de Vivienda Protegida que ha inspeccionado cerca de 8.000 viviendas a lo largo del año 2005 y que está inspeccionando 12.000 nuevas viviendas en el 2006.

En una primea etapa nos estamos centrando en la detección de las patologías más graves socialmente (no ocupación, ventas irregulares y alquileres no autorizados), aunque el objetivo es claro: revisar todo el parque, que en esto momentos ronda las 45.000 viviendas calificadas e inscritas en el Registro de Vivienda Protegida que mantiene el Gobierno Vasco, antes de finalizar el actual Plan Director de Vivienda 2006-2009.

\section{7.- El ejercicio de la potestad sancionador}

El corolario lógico de inspeccionar el uso no puede ser otro que el ejercicio de la potestad sancionadora en aquellos casos en los que se detecten infracciones no prescritas, pudiendo ir las sanciones desde la pequeña sanciones económica, hasta el embargo de la vivienda por impago de las sanciones coercitivas (y readjudicación a demandante inscrito en Etxebide) o la expropiación forzosa por incumpliendo de la función social de las Viviendas Protegidas recogida en la Ley 2/2006, de 30 de junio, de Suelo y Urbanismo de la Comunidad Autónoma del País Vasco. En estos momentos ya se están imponiendo y cobrando sanciones, ya se han recuperado Viviendas Protegidas (de particulares inspeccionados o sancionados que ponen la vivienda a disposición del Gobierno Vasco para que este la compre) y a partir del 20 de septiembre de 2006 quedará expedita la vía de la expropiación ${ }^{19}$.

${ }^{19}$ La materia sancionadora está regulada en estos momentos por las siguientes normas en la Comunidad Autónoma del País Vasco:

Ley $2 / 1998$, de 20 de febrero, de la potestad sancionadora de las Administraciones Públicas de la Comunidad Autónoma del País Vasco.

- $\quad$ Ley 24 / 1977, de expropiación forzosa por incumplimiento de la función social de la propiedad de Viviendas de Protección Oficial (BOE de 4 de abril de 1977).

- $\quad$ Decreto 2114/1968, de 24 de julio, por el que se aprueba el Reglamento para la aplicación de la Ley sobre Viviendas de Protección Oficial.

- $\quad$ Real Decreto 3148/1978, de 10 de noviembre, por el que se desarrolla el RDLey 31/1978 sobre política de vivienda.

- $\quad$ Ley 2/2006, de 30 de junio, de Suelo y Urbanismo de la Comunidad Autónoma del País Vasco.

En breve se sistematizará adecuadamente a través de la Ley de Vivienda de la Comunidad Autónoma del País Vasco que el Gobierno espera remitir a lo largo del 2006 al Parlamento Vasco. 
Todo este conjunto de rasgos hacen peculiar el modelo vasco de Vivienda Protegida y deben ser tenidos en cuenta a la hora de evaluar la eficacia de las reservas de suelo para Vivienda Protegida, pues no se puede comprender el como (reservas) si no se tiene en cuenta el que (que es una Vivienda Protegida en Euskadi).

\section{4. ¿Por qué Vitoria-Gasteiz como ejemplo?}

Se preguntara el lector sobre las razones para escoger Vitoria-Gasteiz como ejemplo en materia de Vivienda Protegida. Las razones son bien sencillas, estamos ante una ciudad de poco más de 220.000 habitantes que desde hace más de una década mantiene una política activa en materia de Vivienda Protegida, hasta el extremo de que en estos momentos el $70 \%$ de las nuevas viviendas iniciadas son Viviendas Protegidas, de tal forma que el Ayuntamiento de Vitoria-Gasteiz y el Gobierno Vasco conjuntamente son los actores principales del mercado residencial tanto en su vertiente de compra (compra de Vivienda Libre en propiedad nueva y usada, compra de Vivienda Protegida, cesión derecho de superficie a 75 años de Vivienda Protegida) como en su vertiente de alquiler (de Vivienda Libre y Vivienda Protegida nueva y usada). Esta circunstancia, la posición de dominio de lo público en materia de vivienda, no se $\mathrm{da}$, al menos que nos conste, en ninguna capital de provincia española y mucho menos si esta es además capital de Comunidad Autónoma como es el caso de Vitoria-Gasteiz.

Por otra parte este predominio de lo público en materia de vivienda en Vitoria-Gasteiz está al margen de los cambios partidistas pues existe un cierto consenso sobre el modelo entre todas las fuerzas políticas del municipio, sin perjuicio de los importantes matices y de la existencia de modelos ideales propios de cada partido. Lo que en Vitoria se llama "cuerdismo" ${ }^{\text {"20 }}$, más allá de sus detractores y defensores, ha marcado, sin lugar a dudas, el devenir urbano de la ciudad. La política de control municipal del suelo y fomento de la promoción de Vivienda Protegida ha tenido, al sostenerse en el tiempo y seguirla las sucesivas administraciones del PNV, EA, PNV y PP, efectos configuradores sobre la personalidad urbana y social de la ciudad. Por otra parte, también desde hace más de una década el Gobierno Vasco sostiene una política especialmente activa en la ciudad alavesa ante la evidente disponibilidad de suelo público para la procura de Vivienda Protegida, haciéndose hincapié en los últimos años en las políticas públicas de alquiler y de movilización de vivienda vacía hacia el alquiler social. Y finalmente, hay que reconocer y ensalzar el que el Ayuntamiento de Vitoria-Gasteiz no haya cesado en la última década y media de suministrar suelo calificado para promover Vivienda Protegida a todos los operadores que trabajan en dicho sector.

Si toda la Comunidad Autónoma del País Vasco disfrutara de las mismas estadísticas de las que disfruta Vitoria-Gasteiz el problema de la vivienda en Euskadi sería mucho menor y ni que decir tiene que si toda España tuviera estadísticas del corte de las vitorianas el problema de la vivienda no estaría sistemáticamente entre las dos o tres preocupaciones de la ciudadanía tal y como nos muestran los datos del CIS.

20 JOSE ANGEL CUERDA fue alcalde de la ciudad durante más de una década y dejo en vivienda, como en otras materias públicas, profunda huella en la ciudad. 
Y no sería así porque la traslación a escala marco de nuestro ejemplo vitoriano micro tendría importante efectos sobre el mercado de la vivienda en general, sobre la consideración del non nato servicio público de vivienda en España, sobre el mercado de la Vivienda Libre e in fine sobre el acceso de la ciudadanía al derecho constitucional a la vivienda ${ }^{21}$.

\section{El impacto de la intervención pública en el mercado de la vivienda en Vitoria-Gasteiz}

\section{1.- Producción masiva de vivienda protegida}

En la última década y media en Vitoria-Gasteiz se han mantenido ritmos de producción de Vivienda Protegida que superan las 1.000 viviendas iniciadas al año. De hecho, desde 1993 hasta el 2005 se han iniciado en Vitoria-Gasteiz 13.653 Viviendas Protegidas. Y a mayor abundamiento en los últimos tres planes directores de vivienda del Gobierno Vasco (cuatrienales, que abarcan el periodo 1994 - 2005) se han iniciado 1.016 Viviendas Protegidas al año. Además el ritmo de producción de estas Viviendas Protegidas ha sido además creciente en el tiempo de forma que en el último Plan Director de Vivienda del Gobierno Vasco se produjo en Vitoria-Gasteiz el 401\% de lo que se produjo en el periodo 1994-1997 y el 248\% de lo producido entre 1998 y el 2001.

Figura $n^{\circ} 1$ : Vivienda Protegida iniciadas en los últimos 12 años en Vitoria-Gasteiz

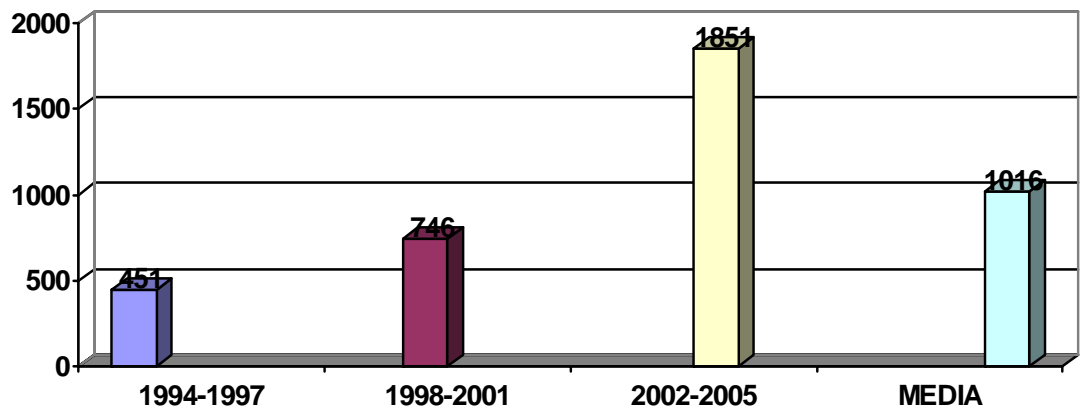

Fuente: Observatorio de la Vivienda del Gobierno Vasco y elaboración propia

Estas cifras implican una cuota de mercado de la Vivienda Protegida en Vitoria-Gasteiz que supera el $65 \%$ marcado por la legislación (hasta la fecha) y llega al entorno del $70 \%$. Mientras que esta cuota de mercado de la Vivienda Protegida es en el conjunto de Euskadi del $30 \%$ y en el Estado se sitúa en el entorno del 8\%. Ni que decir tiene que en Vitoria-Gasteiz la Vivienda

\footnotetext{
${ }^{21}$ Disiente de esta tesis (la capacidad de una importante cuota de mercado de Vivienda Protegida para incidir sobre el mercado de la Vivienda Libre) RODRIGUEZ LOPEZ, JULIO que, en "La vivienda del siglo XXI - Sobre sociología, economía y política", mesa redonda en el marco del Curso de Verano de la Universidad Politécnica de Madrid. "La Vivienda del Siglo XXI. El Futuro de la Vivienda en España" el 13 de julio de 2006 en La Granja de San Ildefonso, sostuvo la imposibilidad de trasladar a escala macro los efectos de fenómenos micro como el de Vitoria-Gasteiz. Sin animo de polemizar con nadie sospecho que si en el conjunto del Estado español la Vivienda Protegida supusiera el $70 \%$ de la nueva vivienda iniciada (en vez del $8 \%$ como ocurre en la actualidad) y si de ese conjunto de Viviendas Protegidas cerca de un tercio fuesen cedidas en alquiler social, otro tercio en derecho de superficie y el tercio final en propiedad y todas ellas fueran Viviendas Protegidas de por vida, tanteables, retactables e inspeccionadas la situación del mercado de la vivienda y del derecho constitucional a disfrutar de una vivienda y adecuada sería muy distinta en España, todo ello con cierta independencia de los ciclos de los tipos de interés de los créditos hipotecarios.
} 
Pública es hegemónica en todos los mercados. Sirvan como ejemplo los siguientes datos referidos al año 2006 relativos a la oferta de los distintos tipos de vivienda y sus respectivas cuotas de mercado.

\section{Cuadro $\mathrm{n}^{\circ}$ 1: Numero de viviendas ofertadas en Vitoria-Gasteiz y cuotas de mercado}

\begin{tabular}{|l|c|l|}
\hline & $\begin{array}{l}\text { Numero de } \\
\text { viviendas ofertadas }\end{array}$ & $\%$ \\
\hline Vivienda Libre nueva & 657 & $14.6 \%$ \\
\hline Vivienda Libre usada & 1808 & $40.2 \%$ \\
\hline Vivienda Protegida nueva venta/der superf. & 2028 & $45.2 \%$ \\
\hline TOTAL VENTA & 4493 & $100 \%$ \\
\hline \multicolumn{2}{|l|}{} \\
\hline Vivienda Libre en alquiler & 146 & $15.1 \%$ \\
\hline Vivienda Protegida en alquiler & 821 & $84.9 \%$ \\
\hline TOTAL ALQUILER & 967 & $100 \%$ \\
\hline \multicolumn{2}{|l|}{} \\
\hline TOTAL GENERAL & 5460 & $100 \%$ \\
\hline Subtotal mercado & $\mathbf{2 6 1 1}$ & $\mathbf{4 7 . 8 \%}$ \\
\hline Subtotal público & $\mathbf{2 8 4 9}$ & $\mathbf{5 2 . 2 \%}$ \\
\hline
\end{tabular}

Fuente: Encuesta del Gobierno Vasco sobre Oferta de Viviendas, Garajes y Locales en la CAPV. $2^{\circ}$ trimestre 2006

y elaboración propia

5.2.- Atención directa a miles de ciudadanos a traves del servicio público de vivienda a precios sociales

Pero el sector público no es solo el que más personas atiende, sino que además las atiende, como no puede ser de otra forma, a un precio socialmente orientado. Sirvan como ejemplo los siguientes datos:

\section{Cuadro n 2: Precios de la vivienda en Vitoria Gasteiz}

\begin{tabular}{|c|c|}
\hline & Precios medios \\
\hline Vivienda Libre nueva & 3.911 euros $/ \mathrm{m}^{2}$ \\
\hline Vivienda Libre usada & 3.795 euros $/ \mathrm{m}^{2}$ \\
\hline Vivienda Protegida nueva venta/der superf. & 1.286 euros $/ \mathrm{m}^{2}$ \\
\hline INDICADOR SINTETICO & 2.679 euros $/ \mathrm{m}^{2}$ \\
\hline Vivienda Libre en alquiler & 885 euros/mes \\
\hline Vivienda Protegida en alquiler ${ }^{22}$ & 304 euros/mes \\
\hline INDICADOR SINTETICO & 391 euros/mes \\
\hline
\end{tabular}

Fuente: Encuesta del Gobierno Vasco sobre Oferta de Viviendas, Garajes y Locales en la CAPV. $2^{\circ}$ trimestre 2006 y elaboración propia

\footnotetext{
${ }^{22}$ En el caso de la Vivienda Social el alquiler medio es de solo 145 euros/mes.
} 
Aprovechamos la ocasión para poner de relieve que en Vitoria-Gasteiz, como en el resto de ciudades españolas, cuando se habla de precios de la vivienda los medios de comunicación y el imaginario colectivo ciudadano solo piensa en los precios de la Vivienda Libre. En muchas ciudades esto es representativo del precio real de la vivienda, pero en un lugar como VitoriaGasteiz no, pues si solo se habla de Vivienda Libre se deja fuera de la ecuación más de la mitad de las viviendas ofertadas (que además suponen la mayor parte de las viviendas de nueva construcción y prácticamente todos los contratos de alquiler).

Por esta razón en el cuadro $\mathrm{n}^{\circ} 2$ hemos introducido lo que llamamos "indicador sintético" que pondera el tamaño de cada tipo de oferta de vivienda con sus precios y nos da como resultado unos precios representativos al incluir tanto la vivienda pública como la privada. En el caso de la vivienda en compra el precio resultante sigue siendo alto $\left(2.679\right.$ euros $\left./ \mathrm{m}^{2}\right)$ pero muy lejano a los 3.911 euros que de forma insistente se pondera en la prensa. $Y$ en el caso de la vivienda en alquiler es claro que, dado el predominio del alquiler público sobre el privado, el precio resultante en el indicador sintético (391 euros/mes) nada tiene que ver con el alquiler de mercado (885 euros/mes).

Como consecuencia de todo lo anterior la oferta de Vivienda Protegida en Vitoria-Gasteiz es capaz de atender de forma directa a miles de ciudadanos a unos precios de compra y alquiler claramente social y, como resultado del peso de lo público en la oferta de vivienda, el conjunto de los precios es mucho menor del que habitualmente se publicita, como demuestran los anteriores "indicadores sintéticos".

Evidentemente también podríamos hablar del elemento cualitativo social que suponen esos 821 alquileres de Vivienda Protegida a precios sociales (casi tres veces menos que el precio de mercado) en términos de cohesión social y de posibilidades emancipatorias para los jóvenes vitorianos. De la misma manera deberíamos poner en valor el hecho de que parte de los alquileres ofertados por las Administraciones Públicas en Vitoria tienen como origen la previa movilización de Vivienda Libre vacía durante al menos un año hacia el alquiler protegido a través del Programa Bizigune. Y finalmente no deberíamos perder de vista que una institución como la Caja de Ahorros de Alava Vital Kutxa se ha involucrado en la tarea del alquiler de Vivienda Protegida a través de promociones propias conveniadas con el Gobierno Vasco (que aporta ayudas públicas al efecto). No solo los factores cuantitativos son relevantes, también debemos prestar atención a la capacidad de crear cohesión social de los factores cualitativos.

\section{3.- Presión sobre el mercado de vivienda libre}

Pero se nos dirá que de nada sirve ofertar mucha Vivienda Protegida a un precio social si la Vivienda Libre sigue siendo cara e inaccesible. Se nos dirá también que la Vivienda Libre en Euskadi en general y en Vitoria-Gasteiz en particular es cara.

La carestía de la Vivienda Libre vitoriana es un hecho indudable, pero lo que generalmente se suele perder de vista (como consecuencia de la situación general en España de la Vivienda Protegida) es que la Vivienda Libre en Vitoria-Gasteiz es un sector minoritario del mercado. Si seguimos los datos antes aportados en el cuadro $n^{0} 1$, por cada Vivienda Libre nueva en oferta (657 en total) el sector público es capaz de ofertar tres veces más (2.028). Por cada Vivienda Libre en alquiler (146 en total) lo público es capaz de ofertar casi seis veces más (821 en total). 
Si se nos permite, el precio de la Vivienda Libre en Vitoria-Gasteiz tiene otro valor social dado que la mayor parte de la necesidad de vivienda (para fines no especulativos, puramente primeras residencias) es cubierta por lo público a precios sociales. Mientras en otras ciudades españolas el precio de la Vivienda Libre es clave para medir el acceso de las personas a la vivienda, pues la Vivienda Protegida es meramente testimonial.

Pero además de satisfacer directamente a la mayor parte de la población vitoriana lo público ejerce una fuerte presión sobre la Vivienda Libre, como están demostrando los nuevos acontecimientos: los promotores privados alaveses y buena parte de las inmobiliarias alavesas reconocen que las ventas de Vivienda Libre están haciéndose hoy a un menor ritmo, los precios empiezan a crecer mucho menos o a estancarse y cuesta mucho más tiempo vender hoy una vivienda.

Esta situación es explicada por los propios operadores privados del mercado alavés en base a dos factores:

- el estrangulamiento de la demanda privada: la gente ya no compra cualquier vivienda a cualquier precio y en el más corto periodo de tiempo posible, bien porque el sistema crediticio ha dejado de financiar esas operaciones hipotecarias bien porque los consumidores no están dispuestos a pagar los altos precios por las Viviendas Libres.

- la existencia de una oferta de Vivienda Protegida potente que le hace directamente la competencia a la Vivienda Libre: por decirlo en el lenguaje de la calle, la gente no está dispuesta a pagar más de 350.000 euros por 85 metros cuadrados cuando sabe que hay posibilidades reales de que a corto o medio plazo le toque una Vivienda Protegida con esos metros por menos de $120.000^{23}$.

Sirva como ejemplo de todo lo anterior que según la Sociedad de Tasación ${ }^{24}$ en VitoriaGasteiz desde el 1 de enero hasta el 30 de junio del 2006 el precio de la Vivienda Libre ha subido un $1.5 \%$ frente a valores muy superiores en el resto de España (8.8\% en Catalunya, 7.7\% en Aragón, $7.4 \%$ en Valencia y Andalucía o 4.4\% en Madrid.

Interpelado por este hecho el concejal de vivienda del Ayuntamiento de Vitoria-Gasteiz (lo citamos, pues cremos que es relevante en este caso, concejal del Partido Popular) la respuesta ha sido clara: "el $70 \%$ de Vivienda Protegida que se está edificando en estos momentos en la ciudad está propiciando que poco a poco se estabilicen los precios de la Vivienda Libre". ¿Quien tiene razón? ¿Los promotores cuando aseguran que la edificación de Vivienda Protegida encarece la Vivienda Libre? ¿O la evidencia fáctica de que cuando la Vivienda Protegida es un porcentaje muy significativo de la vivienda edificada los precios de la Vivienda Libre se estancan y moderan?

\footnotetext{
${ }^{23}$ Perfecta ejemplificación de lo anterior la encontramos en el titular de EL CORREO del pasado 13 de junio: "La demanda de pisos libres cae a la mitad por los sorteos (de VPO)". El artículo explica como las 2000 Viviendas Protegidas que sortean al año en Vitoria-Gasteiz el Ayuntamiento y el Gobierno Vasco hacen que los compradores, especialmente los jóvenes, no estén dispuestos a pagar cualquier precio por la Vivienda Libre.

${ }^{24}$ Citamos esta fuente, sin perjuicio de mantener una radical diferencia con la metodología utilizada por esta sociedad para captar sus datos en la Comunidad Autónoma del País Vasco.
} 


\section{Conclusiones a extraer del ejemplo alavés a escala estatal}

Este escenario en el que hemos entrado recientemente (demanda privada de vivienda estrangulada y por lo tanto progresivamente elástica -frente a la inelasticidad pasada-, oferta de vivienda privada que tiene que procesar este nuevo escenario -y rebajar sus pretensiones de beneficio ante el riego de no colocar el producto- y oferta de Vivienda Protegida poderosa) tiene grandes virtualidades para solucionar el problema de la vivienda en Vitoria-Gasteiz y por ende en Euskadi a medio plazo ${ }^{25}$.

Uno de los efectos, nunca destacados, de la producción de Vivienda Protegida es, como trata de mostrar este trabajo, la presión de una vivienda pública fuerte sobre el mercado de vivienda privado. Algo tendrá que ver el papel de los público, la masiva producción de Vivienda Protegida (y si se nos permite, protegida de verdad) en el menor incremento de los precios de la Vivienda Libre en Euskadi en relación al conjunto del Estado español ${ }^{26}$.

\section{Figura $n^{\circ}$ 2: Incremento del precio de la vivienda libre 2002-2005 por CCAA}

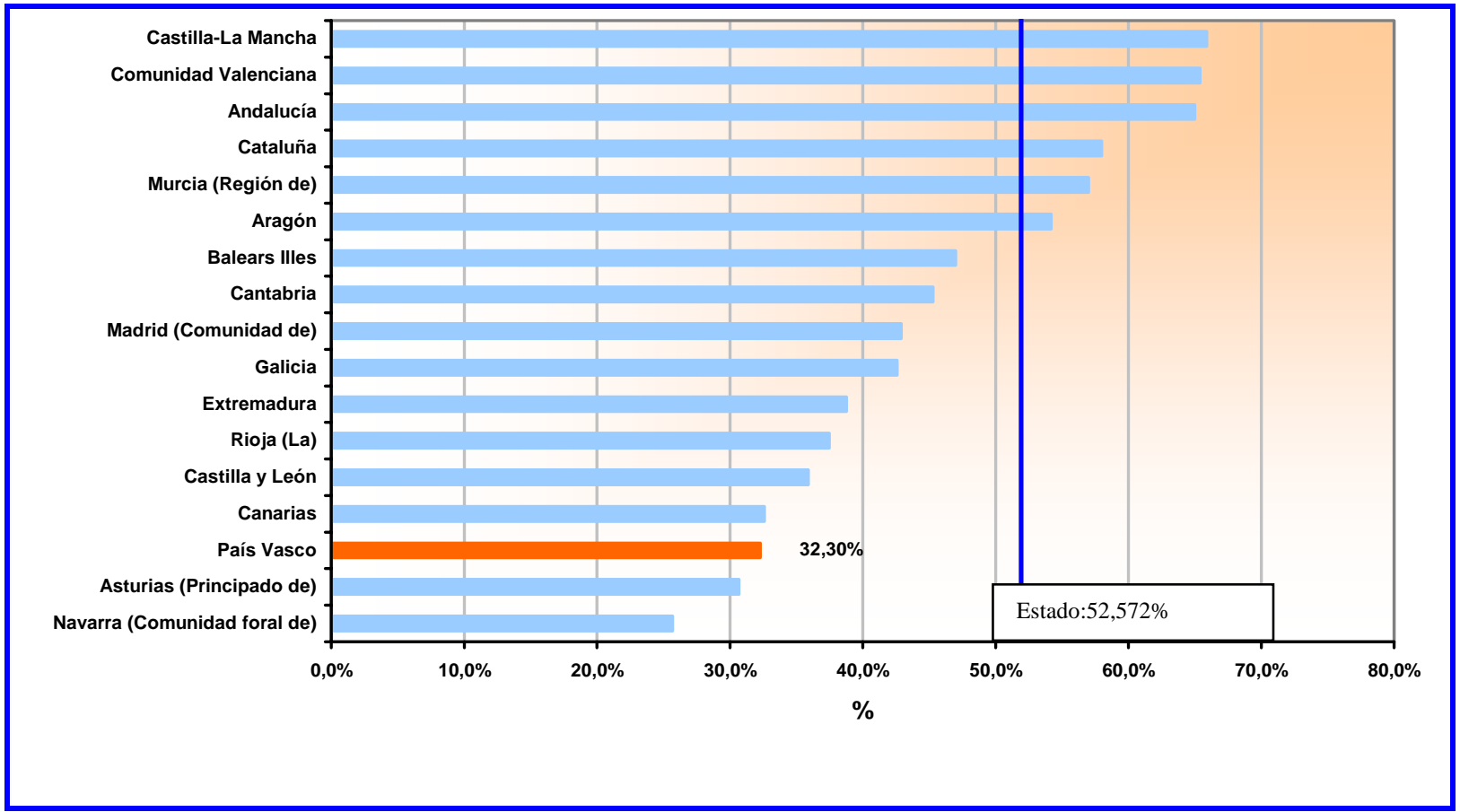

Fuente: Ministerio de Vivienda.

\footnotetext{
${ }^{25}$ A modo de ejemplo de la eficacia indirecta (la directa siempre la da la cobertura a la población a través de Vivienda Protegida) de la política de vivienda del Gobierno Vasco podemos citar el titular de EL DIARIO VASCO del pasado 22 de octubre "El País Vasco fue una de las Comunidades donde menos se encarecieron los precios (de la Vivienda Libre)" o el DIARIO DE NOTICIA DE ALAVA del mismo día "Euskadi, una de las Comunidades donde menos se encarece la Vivienda Libre".

${ }^{26}$ Sobre los efectos de la producción de Vivienda Protegida sobre el precio de la Vivienda Libre consultar la obra de TRILLA BELLART, CARME. Entre otros se puede citar La vivienda necesaria. ¿Fracaso del modelo español del vivienda protegida?, presentado en el Curso "Derecho a la vivienda y la política Local", Curso de Verano de la Universidad Complutense, El Escorial, 28 de julio de 2005, gráfico 4.9 en la pag. 21.
} 
No hay en nuestra defensa de la Vivienda Protegida fe sin base, sino comprobación empírica de los efectos positivos de la Vivienda Protegida sobre la calidad de vida de amplias capas de la sociedad vasca en general y vitoriana en particular. Si lo que debe procurar el derecho público en materia urbana es acceso a la vivienda a nivel micro y cohesión social a nivel macro no cabe la menor duda de que las reservas de suelo para Vivienda Protegida son un instrumento necesario (aunque no suficiente) para una política de vivienda que pretende seguir los mandatos constitucionales. La técnica jurídica existe (de hecho es vieja) y se puede aplicar (de hecho, el ejemplo vitoriano demuestra que se está ya aplicando). Ahora solo hace falta que los operadores políticos, económicos y administrativo se pongan manos a la obra.

Todo lo que hemos tratado de exponer en estas páginas no podría entenderse si no se tienen en cuenta que ésta es una batalla, importante, pero una más, de las que hay que luchar en la defensa del Estado Social. La radicalidad y novedad del marco normativo de la vivienda protegida en Euskadi no se puede entender si no es en la perspectiva de una apuesta por el Welfare State casi cien años después de que HERMAN HELLER ${ }^{27}$ lo definiese teóricamente y solo cincuenta años después de que FRIEDMAN, HAYECK, LIPSET, BELL, NISBET o HUNTINGTON ${ }^{28}$ tratarán de socavar sus cimientos y mandarlo a un rincón de la historia.

Hoy el Estado Social sigue siendo la única manera de conciliar libertad civil con igualdad social y política. Como siempre nos recuerda el maestro DIAZ, ELIAS ${ }^{29}$ no hay verdadero Estado de Derecho sin un fuerte Estado Social. Tampoco debemos perder de vista el excelente trabajo de NAVARRO, VICENS ${ }^{30}$ que habla con claridad, ya desde su propio título (Bienestar insuficiente y democracia incompleta) de la relación entre Estado social y democracia.

El modelo de Vivienda Protegida vasco (y en especial el vitoriano) es un modelo atípico (pues solo tiene homólogos parciales o totales en las Comunidades Autónomas de Asturias, Catalunya y Navarra), pero ni utópico ni ucrónico: se da aquí y ahora en la Euskadi de la primera década del nuevo siglo. Puede que sea un modelo a contracorriente de la política de muchas otras Comunidades Autónomas, pero lo que no se podrá negar es que no es un modelo a contracorriente del dictado constitucional, más bien al contrario es un modelo que trata de cumplir en su totalidad el mandato constitucional que el artículo 47 dirige a los poderes públicos.

\section{BIBLIOGRAFIA}

- BASSOLS COMA, MARTIN Consideraciones sobre el derecho a la vivienda en la Constitución española de 1978, RDU, Madrid, 1983.

- BELTRAN DE FELIPE, MIGUEL Intervención Administrativa en la vivienda, Editorial Lex Nova, Valladolid, 2000.

- $\quad$ BURON CUADRADO, Fo JAVIER

\footnotetext{
${ }^{27}$ HELLER, HERMAN Teoría del Estado, Fondo de Cultura, México, 1998

${ }^{28}$ Se puede obtener una visión del movimiento neoconservador, entre otras muchas fuentes, a través de VALLESPIN, FERNANDO Historia de la Teoría Política, Alianza Editorial, 1993.

${ }^{29}$ DIAZ, ELIAS Estado de Derecho y sociedad democrática, 1966.

${ }^{30}$ NAVARRO, VICENS Bienestar insuficiente, democracia incompleta, Anagrama, Barcelona, 2002.
} 
- "La Vivienda Protegida en Euskadi, ¿un modelo a contracorriente?", Cuadernos de Derecho Local (Fundación Democracia y Gobierno Local), no 9, octubre 2005.

- "La política de viviendas del Gobierno Vasco" en Documentación Social no 138, julioseptiembre 2005, Revista de Estudios Sociales y de Sociología Aplicada.

- DIAZ, ELIAS Estado de Derecho y sociedad democrática, 1966.

- $\quad$ GAMBARO, A Propieta privata e disciplina usbanistica, Zanichelli, Bolonia, 1977.

- GARRIDO, PILAR El derecho a disfrutar de una vivienda digna y adecuada, en Los principios rectores de la política social y económica, Editorial Biblioteca Nueva, Madrid, 2004.

- GOMÁ, RICARD Las políticas de viviendas en las Comunidades Autónomas, dentro del volumen Estado de Bienestar y Comunidades Autónomas, Editorial Tecnos, Madrid, 2003.

- GOMEZ JIMENEZ, MARIA LUISA La intervención Administrativa en la Vivienda en España 1938-2005, Editorial Montecorvo, Madrid, 2006.

- HELLER, HERMAN Teoría del Estado, Fondo de Cultura, México, 1998

- JIMÉNEZ BLANCO, ANTONIO El derecho a una vivienda digna y adecuada en Comentarios a la Constitución social y económica de España, Editorial Comares, Granada, 2002.

- MUÑOZ CASTILLO, JOSE El derecho a una vivienda digna y adecuada; Editorial Colex, Madrid, 2000

- NAVARRO, VICENS Bienestar insuficiente, democracia incompleta, Anagrama, Barcelona, 2002.

- PAREJO, luciano y GARCIA DE ENTERRÍA, EDUARDO Lecciones de Derecho Urbanístico, Madrid, Civitas, 1981.

- PISARELLO, GERARDO Vivienda para todos, un derecho en (de)construcción, Editorial Icaria, Barcelona, 2003.

- PONCE SOLÉ, JULI

- Solidaridad, cohesión social y derecho público, a propósito de las reservas legales de Vivienda Protegida como instrumento de desarrollo urbanístico sostenible, II Seminario Pensando lo local en el nuevo siglo, Fundació Carle Pi i Sunyer, 5 y 6 de febrero de 2004.

- Algunas reflexiones sobre la competencia en materia de vivienda y las tendencias actuales en su ejercicio, Informe Comunidades Autónomas 2004, Instituto de Derecho Público, Barcelona 2005.

- ROGER FERNANDEZ, GERARDO La gestión del suelo para la vivienda social, en el curso de verano de la Universidad Complutense "El derecho a la vivienda y la política local", El Escorial (Madrid), 25 a 29 de julio de 2005.

- TRILLA BELLART, CARME ¿Fracaso del modelo español del vivienda protegida?, presentado en el Curso "Derecho a la vivienda y la política Local", Curso de Verano de la Universidad Complutense, El Escorial, 28 de julio de 2005.

- VALLESPIN, FERNANDO Historia de la Teoría Política, Alianza Editorial, 1993.

- VILLAR EZCURRA, JOSE LUIS La protección pública a la vivienda, Editorial Montecorvo, Madrid, 1981. 